\title{
Refuge
}

Canada's Journal on Refugees

Revue canadienne sur les réfugiés

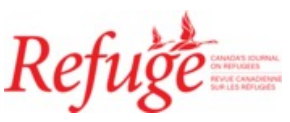

\section{Ethical Considerations: Research with People in Situations of Forced Migration}

\section{Christina Clark-Kazak}

Volume 33, Number 2, 2017

URI: https://id.erudit.org/iderudit/1043059ar

DOI: https://doi.org/10.7202/1043059ar

See table of contents

Publisher(s)

Centre for Refugee Studies, York University

ISSN

0229-5113 (print)

1920-7336 (digital)

Explore this journal

Cite this document

Clark-Kazak, C. (2017). Ethical Considerations: Research with People in Situations of Forced Migration. Refuge, 33(2), 11-17.

https://doi.org/10.7202/1043059ar

\section{Article abstract}

Research can contribute to better understanding of the forced migration experience to inform policy and programming, but it can also cause inconvenience and harm to research respondents.[1] In situations of forced migration, the stakes are particularly high because of precarious legal status, unequal power relations, far-reaching anti-terrorism legislation, and the criminalization of migration. In response, the Canadian Council for Refugees, York University's Centre for Refugee Studies, and the Canadian Association for Refugee and Forced Migration Studies collaborated to complement established ethical principles with specific ethical considerations for research with people in situations of forced migration. This document highlights our guiding principles and applies the ethical concepts of voluntary, informed consent; respect for privacy; and cost-benefit analysis. It is of relevance to anyone involved in gathering information-whether in an academic or community setting - and those who are asked to take part in research.
Copyright (c) Refuge: Canada's Journal on Refugees, 2017

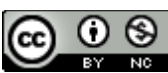

This document is protected by copyright law. Use of the services of Érudit (including reproduction) is subject to its terms and conditions, which can be viewed online.

https://apropos.erudit.org/en/users/policy-on-use/ 


\title{
Ethical Considerations: Research with People in Situations of Forced Migration
}

\author{
CHRISTINA CLARK-KAZAK, WITH THE CANADIAN COUNCIL FOR REFUGEES, \\ THE CANADIAN ASSOCIATION FOR REFUGEE AND FORCED MIGRATION STUDIES, AND \\ YORK UNIVERSITY'S CENTRE FOR REFUGEE STUDIES ${ }^{1}$
}

\section{Preamble}

$\mathrm{R}$ esearch involving people in situations of forced migration deepens our understanding of their experiences and has the potential to inform evidence-based decision-making, but also poses particular ethical challenges and opportunities. This document is intended to provide researchers, community organizations, and people in situations of forced migration with information on the particularities of forced migration contexts to complement established ethical principles and frameworks on research with human subjects more generally. They draw on good practices identified in a scan of civil society and government documents and academic literature (see appendix 3 for a list of resources).

Forced migration research contexts are particular several ways:

1. People who flee across borders are subject to legal rights and opportunities that are different from those for citizens born in the host country. The right to remain in the host country can be revoked or jeopardized on the basis of data collected during research. Given this precarious legal status, researchers working with people in situations of forced migration need to carefully consider ethical obligations to minimize risks.

2. Displaced people are often in situations of unequal power relations where they depend on sponsors, service providers, and/or the government for survival and/or legal status. This extreme dependence may call into question the voluntary nature of consent to participate in research conducted by, or in partnership with, such organizations.

3. Given the operation of groups deemed to be engaged in terrorism ${ }^{2}$ in countries of origin and asylum, research may run into conflict with anti-terrorist legislation. For example, research respondents may disclose links to, or express sympathy with the objectives of, groups deemed to have terrorist aims. Because researchers are not protected by similar legal privileges for doctors and lawyers, there may be limits to confidentiality of information, posing ethical challenges.

4. Throughout the process of asylum, displaced people are called upon to tell their story many times: to immigration officials, to legal professionals, to service providers, and to decision-makers. Researchers' questions may add to the burden of recalling painful experiences of conflict, violence, violations, and abuse.

5. While academic research has the potential to contribute to improved policy and programming for people in situations of forced migration, findings are not always shared with displaced people and non-academic partners in an accessible and timely manner.

\section{Definitions}

In this document, research is defined as any activity that involves data collection and knowledge creation with and by people in situations of displacement. This includes, but is not limited to, interviews, focus group discussions, surveys, experiments, observation, and access to case files, administrative data, and auto-ethnographies involving third-party participant data collection. It should be noted that not all of these research activities are necessarily subject to Research Ethics Board approval; however, this document sets out principles of good practice that should be considered whenever research is undertaken in contexts of forced migration.

"People in situations of forced migration" includes a 
broad spectrum of displacement, including refugee claimants, those with refugee status, people whose refugee claims have been rejected, trafficked persons, and internally displaced persons. The ethical considerations set out in this document apply to all groups who have been forced to leave their homes, not just those individuals who have refugee status.

\section{Guiding Principles}

Our research with people in situations of forced migration will be guided by the following key principles:

\section{Equity}

We will strive to make our research relationships as equitable as possible, by being conscious of power dynamics and guarding against risks of abuse of power.

- We will select research respondents and research teams on the basis of equitable principles.

- We will include a diversity of perspectives and avoid assumptions based on gender, sexual orientation, age, ability, religion, culture, ethnicity, or nationality.

- We will be aware of our own positionality, biases, and responsibility in the research process.

- We will work to develop mutual trust in relationships.

\section{Right to Self-Determination}

We will respect and support the right of people in contexts of forced migration to make their own decisions about their lives and the degree of participation in research processes.

- We will privilege the rights and well-being of research respondents over the objectives of the research.

- We will uphold the dignity of our respondents in our portrayal of them-individually and collectively.

\section{Competence}

We will respect our duty to act competently.

- We will select appropriate research methods.

- We will acquire appropriate cultural and diversity understanding.

- We will screen, train, and supervise research assistants and interpreters.

- We will provide research respondents with accurate information on their rights.

- We will recognize our own limits and make appropriate referrals when research respondents demonstrate needs and/or request information.

- We will accept a duty of care.

\section{Partnership}

We will include relevant partners in our research throughout the research process: from design to data collection and analysis to dissemination of results.

- We will develop appropriate protocols and mechanisms to ensure full participation of relevant partners.

- We will decide in advance on culturally appropriate conflict resolution mechanisms in case of disputes over methods, design, or dissemination.

- We will promote co-ownership of the research and respectfully acknowledge each partner's contributions. In cases where co-authorship is not possible, such as degree requirements that students be solely responsible for writing papers or dissertations, this will be clearly explained to all involved in the research from the beginning of the research process.

\section{Application of Key Ethical Principles to Research in Contexts of Forced Migration}

Voluntary, Informed Consent

All research respondents must voluntarily and formally consent to participate in research after having been informed of the potential risks and benefits of their participation. They must be able to withdraw from the research at any time. The following issues should be taken into account when obtaining voluntary, informed consent from people in situations of forced migration:

- Displaced people who have had negative interactions with authorities and/or from different cultural traditions may be suspicious of written consent forms. Oral consent should be provided as an option in these cases, with clear procedures on how to obtain and record such oral consent.

- Researchers may rely on service providers or refugee organizations to gain access to potential respondents. However, only the research respondents themselves can consent to participate. In cases where gatekeepers have been involved, it is important that potential research respondents understand their right to refuse to participate at any stage in the research process, and that this refusal will not affect service provision or level of care. Further consideration should also be given to how the anonymity of the participants will be guaranteed, given that they have been referred by an agency/ service provider. This must be clearly articulated in both the protocol and consent process.

- While financial compensation can be offered for people's time and/or child care and/or transportation costs in order to remove barriers to participation, it should be proportionate and reasonable. Displaced people in financial need should not feel pressured to participate 
for financial reasons. Compensation must not be tied to or depend upon completion of the research study.

- Research rarely directly benefits individual respondents. This needs to be clearly explained to people in situations of forced migration, so that they do not participate only in the hope that their participation will bring direct material, legal, or other benefits.

- Respondents should be made aware of the financial, emotional, community/social, and other risks of participating, particularly the limits of confidentiality on any disclosure of criminality or self-harm, as discussed below.

\section{Confidentiality and Privacy}

Researchers have a duty to protect respondents' personal information and not disclose any identifying characteristics that would compromise anonymity, especially if sample sizes are small. In particular, the following considerations should apply to research in forced migration contexts:

- Researchers have limited legal protection when third parties use subpoenas in criminal proceedings and civil litigation. This issue is particularly significant, given the criminalization of migration and far-reaching anti-terrorism legislation. Research subjects should be made aware of these risks. Researchers should avoid collecting potentially incriminating data and only those directly relevant to the research topic. These data should be completely anonymized immediately upon collection, so that no information can be directly linked to a particular individual. Wherever and whenever possible, researchers should avoid collecting data with personal identifiers.

- Researchers and respondents should also be aware that electronic survey tools with servers that are housed outside of Canada are subject to third country legislation, including, in some cases, access to all data collected. In these cases, the consent form should include information on access and storage and potential limits to confidentiality.

- In some cases, research respondents will spontaneously reveal adverse incidents, such as abuse, exploitation, and self-harm. The researcher should make clear the limits of confidentiality in these cases, especially in cases of disciplinary norms where researchers have a duty to report, as well as have a strategy for referral to external resources in case of such incidents.
- In some cases, the identification of research subjects can have serious consequences for their safety, wellbeing, migration status, and/or eligibility for services. In these instances, confidentiality of information is paramount. Researchers should take extra care to encrypt and securely store data and to remove any characteristics that could identify research subjects, including by association.

- While audiovisual materials can be important data, they also pose particular challenges in confidentiality and anonymity. They should be used with caution, and only with the explicit permission of all people appearing in these materials. Research subjects should have the opportunity to request the destruction of such audiovisual materials in which they appear at any time.

- Interpreters, researchers, and others involved in the research process must sign a confidentiality agreement.

- Where research subjects wish to be named in the research, researchers must respect this desire for selfdetermination and find ways to do so that does not compromise the anonymity of others who do not wish to be identified.

\section{Minimize Harm and Maximize Benefits of Research}

- Researchers should build on and collaborate with similar research to avoid over-researching some populations.

- Researchers should avoid sensitive and potentially re-traumatizing topics-such as sexual violence and torture-except when they are directly relevant to the research topic. In these cases, external resources and services must be identified and readily available in case a referral is necessary. All efforts will be made to minimize harm.

- All efforts should be made to include a diversity of perspectives in research studies, with specific recruitment strategies and methodology to include differential perspectives and research needs based on age, gender, sexuality, ability, class, race, education, literacy, and language.

- Researchers should ensure maximum dissemination of research results in relevant languages and in multiple media (oral, written, visual) and clearly indicate to research subjects where such research results will be available. 


\section{Appendix 1}

\section{Checklist for Researchers}

1. Do I need ethics approval for this project? If so, how can this be obtained?

2. Where applicable, have I shared my ethics protocol with relevant partners?

3. Who will benefit from this research?

4. Who else is doing research on this topic and with this population? Have we coordinated efforts to avoid over-researching?

5. What are the potential limits to confidentiality? What strategies do I have in place to deal with situations where criminality, exploitation, or self-harm are disclosed?

6. Who is not included in my proposed research? How can I facilitate the participation of these individuals?

7. How will I include relevant partners in all phases of my project: from design to dissemination? What mechanisms and protocols are in place to ensure full participation?

8. Have I factored into my project budget compensation for the time and other resources non-academic partners invest in research, including as respondents, serving on advisory committees, recruiting other respondents, and facilitating the participation of other respondents?

\section{Appendix 2}

Checklist for Organizations and Individuals Working in Contexts of Forced Migration Who Are Approached to Participate in Research

1. If required, has the researcher obtained ethics clearance from the home institution? If so, has the researcher provided a copy of the ethics approval documents, as well as the contact information for the institution's research ethics board? If no ethics clearance processes are in place, how will the principles of consent, confidentiality, and harm reduction be assessed and applied?

2. Does the researcher have an appropriate voluntary, informed consent process?

3. How will we communicate with our clients and colleagues so that they understand that they do not have to participate in the research in order to continue to receive our services?

4. How will the privacy and confidentiality of data be ensured?

5. What are the processes in place in case research reveals criminality, exploitation, or self-harm?

6. Who is not included in the research? What modifications and strategies could facilitate the participation of these individuals?

7. How will the researcher share the results of the research, including anonymized data? 


\section{Appendix 3: Related Resources ${ }^{3}$}

Related Ethical Guidelines and Protocols

Canadian Council for Refugees. "Code of Ethics for Groups Involved in the Private Sponsorship of Refugees." 2010. http://ccrweb.ca/en/code-ethics-groups-involved-privatesponsorship-refugees.

European Commission Directorate-General for Research and Innovation. "Guidance Note: Research on Refugees, Asylum Seekers \& Migrants." n.d. http://ec.europa.eu/ research/participants/data/ref/h2020/other/hi/guide_ research-refugees-migrants_en.pdf.

Human Rights Watch. "About Our Research." n.d. https:// www.hrw.org/about-our-research.

International Labour Organization. "Handbook for ActionOriented Research on the Worst Forms of Child Labour Including Trafficking in Children." 2000. http://www.ilo. org/asia/whatwedo/publications/wCMs_160996/lang-en/index.htm.

- - - Hard to See, Harder to Count: Survey Guidelines to Estimate Forced Labour of Adults and Children. Geneva: ILO, 2011. http://un-act.org/wp-content/uploads/2015/06/ Harder-to-See-Harder-to-Count.pdf.

Joint IDP Profiling Service, Danish Refugee Council. "Overview of a Profiling Exercise: 'A Step-by-Step.” n.d. https:// $\mathrm{drc} . \mathrm{dk} / \mathrm{media} / 1214516 /$ step-by-step-idp-profiling.pdf.

Metropolis British Colombia. "MBC Charter of CommunityUniversity Research Principles." n.d. http://mbc.metropolis.net/assets/uploads/files/MBC_Community_Charter. pdf.

PICUM. "Some Guidelines for Assisting Undocumented Migrants" 2112. http://picum.org/picum.org/uploads/file_ /ethicalguidelinesinenglish.pdf.

UNICEF. Guidelines on the Protection of Child Victims of Trafficking. New York: UNICEF Technical Notes, 2006. http://www.unicef.org/ceecis/o610-Unicef_ Victims_Guidelines_en.pdf.

World Health Organization. wHo Ethical and Safety Recommendations for Researching, Documenting and Monitoring Sexual Violence in Emergencies. Geneva: wHo, 2007. http://www.who.int/gender/documents/oms_Ethics\& Safety1oAugo7.pdf.

\section{Academic Literature}

Bakewell, Oliver. "Editorial Introduction. Researching Refugees: Lessons from the Past, Current Challenges and Future Directions." Refugee Survey Quarterly 26, no. 3 (2007): 6-14.

Bertrand, Didier. "The Autobiographical Method of Investigating the Psychosocial Wellness of Refugees." In Psychosocial Wellness of Refugees: Issues in Qualitative and
Quantitative Research, ed. F.L. Ahearn, 88-104. New York: Berghahn Books, 2000.

Bloch, Alice. "Carrying Out a Survey of Refugees: Some Methodological Considerations and Guidelines." Journal of Refugee Studies 12, no. 4 (1999): 367-83.

Block, Karen, Elisha Riggs, and Nick Haslam, eds. Values and Vulnerabilities: The Ethics of Research with Refugees and Asylum Seekers. Toowong, Australia: Australian Academic, 2013.

Block, Karen, Deborah Warr, Lisa Gibbs, and Elisha Riggs. "Addressing Ethical and Methodological Challenges in Research with Refugee-Background Young People: Reflections from the Field." Journal of Refugee Studies 26, no. 1 (2013): 69-87.

Bouquet, Brigitte, and Marcel Jaeger. "Tensions entre mise en oeuvre des politiques migratoires et questions éthiques du travail social." Hommes et migrations 129 (2011): 10-21.

Clark-Kazak, Christina. "Power and Politics in Migration Narrative Methodology: Research with Young Congolese Migrants in Uganda." Migration Letters 6, no. 2 (2009): 175-82.

de Haene, Lucia, Hans Grietens, and Karine Verschueren. "Holding Harm: Narrative Methods in Mental Health Research on Refugee Trauma." Qualitative Health Research 20, no. 12 (2010): 1664-76.

Doná, Giorgia. "The Microphysics of Participation in Refugee Research." Journal of Refugee Studies 20, no. 2 (2007): 210-29.

Dyregrov, Kari, Atle Dyregrov, and Magne Raundalen. "Refugee Families: Experience of Research Participation." Journal of Traumatic Stress 13, no. 3 (2000): 413-26.

Ellis, B. Heidi, Maryam Kia-Keating, Siraad Aden Yusuf, Alisa Lincoln, and Abdirahman Nur. "Ethical Research in Refugee Communities and the Use of Community Participatory Methods." Transcultural Psychiatry 44, no. 3 (2007): 459-81.

Hugman, Richard, Linda Bartolomei, and Eileen Pittaway. "Human Agency and the Meaning of Informed Consent: Reflections on Research with Refugees." Journal of Refugee Studies 24, no. 4 (2011): 655-71.

Hugman, Richard, Eileen Pittaway, and Linda Bartolomei. "When 'Do No Harm' Is Not Enough: The Ethics of Research with Refugees and Other Vulnerable Groups." British Journal of Social Work 41, no. 7 (2011): 1271-87.

Jacobsen, Karen, and Loren Landau. "The Dual Imperative in Refugee Research: Some Methodological and Ethical Considerations in Social Science Research on Forced Migration." Disasters 27, no. 3 (2003): 185-206.

- - Researching Refugees: Some Methodological and Ethical Considerations in Social Science and Forced Migration. Geneva: UNHCR, 2003. 
Knight, Lesley-Anne. "Humanitarian Crises and Old Age: Guidelines for Best Practice." Age and Ageing 29, no. 4 (2004): 293-5.

Lammers, Ellen. "Researching Refugees: Preoccupations with Power and Questions of Giving." Refugee Survey Quarterly 26, no. 3 (2007): 72-81.

Leaning, Jennifer. "Ethics of Research in Refugee Populations." Lancet 357, no. 9266 (2001): 1432-3.

Lott, Jason P. "Module Three: Vulnerable/Special Participant Populations." Developing World Bioethics 5, no. 1 (2005): $30-54$.

Macchiavello, M. Urban Forced Migrants in Kampala: Methodologies and Ethical and Psychological Issues. Johannesburg, Forced Migration Studies Programme, University of the Witwatersrand, 2003.

Mackenzie, Catriona, Christopher McDowell, and Eileen Pittaway. "Beyond 'Do No Harm': The Challenge of Constructing Ethical Relationships in Refugee Research." Journal of Refugee Studies 20, no. 2 (2007): 299-319.

Mulumba, Deborah. "The Challenges of Conducting Research among Rural-Based Refugees in Uganda." Refugee Survey Quarterly 26, no. 3 (2007): 61-71.

Penz, G. Peter. Ethics and Social Science in the Analysis of Development-Induced Displacement: Issues of Theory and Methodology. Toronto: Centre for Refugee Studies, 2002.

Perry, Kristen H. "Ethics, Vulnerability, and Speakers of Other Languages: How University IRBS (Do Not) Speak to Research Involving Refugee Participants." Qualitative Inquiry 17, no. 10 (2011): 899-912.

Polzer Ngwato, Tara. "Collecting Data on Migrants through Service Provider Ngos: Towards Data Use and Advocacy." Journal of Refugee Studies 26, no. 1 (2013): 144-54.

Refugee Studies Centre, Queen Elizabeth House, University of Oxford. "Ethical Guidelines for Good Research Practice." Refugee Survey Quarterly 26, no. 3 (2007): 162-72. (Adapted from Association of Social Anthropologists, "Ethical Guidelines for Good Research Practice," http:// www.theasa.org/ethics/guidelines.shtml.)

Rodgers, Graeme. 'Hanging Out' with Forced Migrants: Methodological and Ethical Challenges." Forced Migration Review 21 (2005): 48-9.

Rousseau, Cecile, and Laurence Kirmayer. "From Complicity to Advocacy: The Necessity of Refugee Research." American Journal of Bioethics 10, no. 2 (2010): 65-7.

Samaddar, Ranabir. "Power, Fear, Ethics." Refugee Watch 14 (2001): 12-20.

Schweitzer, Robert, and Zachary Steel. Researching Refugees: Methodological and Ethical Considerations in Doing Cross-cultural Research: Ethical and Methodological Perspectives, ed. P. Liamputtong, 87-102. Springer, 2008.
Smith, Valerie J. "Ethical and Effective Ethnographic Research Methods: A Case Study with Afghan Refugees in California." Journal of Empirical Research on Human Research Ethics 4, no. 3 (2009): 59-72.

Spoljar-Vrzina, S.M., S. Martic-Biocina, and M.K. Gilliland. "The Anthropological Approach to the Study of the Uprooted in Croatia: Some Guidelines for Future Projects." Collegium Antropologicum 20, no. 2 (1996): 293-9.

Temple, Bogusia, and Rhetta Moran, eds. Doing Research with Refugees: Issues and Guidelines. Bristol: Policy, 2011.

Thomas, Samantha, and Sarah Byford. "Research with Unaccompanied Children Seeking Asylum." British Medical Journal 327, no. 7428 (2003): 1400.

Tomkinson, Sule. "Doing Fieldwork on State Organizations in Democratic Settings: Ethical Issues of Research in Refugee Decision Making." Forum Qualitative Sozialforschung / Forum: Qualitative Social Research 16, no. 1 (2015).

Yu, Elena S.H., and William T. Liu. "Methodological Problems and Policy Implications in Vietnamese Refugees Research." International Migration Review 20, no. 2 (1986): 483-501.

Zimmerman, Cathy. wHO Ethical and Safety Recommendation for Interviewing Trafficked Women. London: Health Policy Unit, London School of Hygiene \& Tropical Medicine Daphne Programme of the European Commission World Health Organization, 2003.

Zion, Deborah, Linda Briskman, and Bebe Loff. "Returning to History: The Ethics of Researching Asylum Seeker Health in Australia." American Journal of Bioethics 10, no. 2 (2010): 48-56.

\section{Notes}

1 Prepared by Christina Clark-Kazak and adopted by the Executive Committees of the Canadian Council for Refugees (CCR), the Canadian Association for Refugee and Forced Migration Studies (CARFMS), and York University's Centre for Refugee Studies (CRS). The following people were on the project committee and contributed to the ideas contained within this document: Tanya Aberman, Idil Atak, Michael Casasola, Sherman Chan, Alison CollinsMrakas, Janet Dench, John Dubé, Sue Grafe, Celia HaigBrown, Jennifer Hyndman and Michaela Hynie. We gratefully acknowledge the contributions of participants in the workshop at the CCR Fall Consultation in November 2016, at which Johanna Reynolds and John Carlaw also facilitated groups. This document also draws inspiration from the CCR's code of ethics for private sponsorship. Funding was provided by the Social Sciences and Humanities Research Council; Immigration, Refugees and Citizenship Canada; and, Refuge: Canada's Journal on Refugees. We 
acknowledge the in-kind contributions of CCR, CARFMS, CRS and MOSAIC.

2 Anti-terrorist legislation is far-reaching and changeable. It is important for people working in forced migration contexts to acknowledge these laws and their implications for their work. This document in no way validates this legislation.
3 Collated by Tanya Aberman, with previous research assistance provided by Chizuru Nobe Ghelani.

Christina Clark-Kazak is associate professor in the School of Public and International Affairs, University of Ottawa. She may be contacted at cclarkka@uottawa.ca 